\title{
Histopathological and Clinicopathological Co-Relation of Non-Neoplastic Cystic Lesions in Surgically Removed Ovaries
}

\author{
Dipti Manojbhai Patel and Seema N. Baxi*
}

Dept. of Pathology, Government Medical College, Bhavnagar, Gujarat, India

\begin{abstract}
Introduction: Neoplastic ovarian lesions have been extensively studied, but less attention is paid to non-neoplastic cystic lesions. Though follicular cysts are the most common of the non-neoplastic cysts, the \% of occurrence of individual non-neoplastic lesions is not known. Also, often there is dilemma in reporting the exact type of nonneoplastic cyst. This study was planned with the objectives of assessing percentage of non neoplastic cystic ovaries, determining the morphological forms and relation of the various cysts with age of patient, and to detect whether multicystic non neoplastic lesions are more frequent in present day.
\end{abstract}

Materials and Methods: A prospective hospital based cross sectional non-neoplastic ovarian cysts study was done between January to June 2019 in a tertiary hospital.All hysterectomy specimens with the accompanying ovary/ovaries and oophorectomy specimen were included. Microscopic features were assessed. Data was tabulated in MS excel sheet. Percentage of occurrences of age, size, morphological type, laterality and complaints were calculated.

Result: $50 \%$ of 193 ovaries had non neoplastic cystic lesions. Non neoplastic cysts were associated with fibroid in 54\%, DUB in 17\% and adenomyosis in $16 \%$ cases. They were seen commonly during reproductive age group( $83 \%$ ). Post-menopausal age showed $16 \%$ cases. $86 \%$ of the non neoplastic ovarian cystic lesions were unilateral. $20 \%$ non neoplastic cystic lesions were of $<1 \mathrm{~cm}, 74 \%$ were $1-5 \mathrm{~cm}$ in size and $5 \%$ were larger than $5 \mathrm{~cm}$.Morphologically $40 \%$ were follicular lesions, $32 \%$ were simple serous cysts, $14 \%$ were haemorrhagic cysts, $8 \%$ corpus luteal cysts and $2 \%$ each theca lutein and epithelial inclusion cysts.

Conclusion: Non neoplastic cystic ovaries comprised $50 \%$ of all ovarian lesions, $83 \%$ were seen during reproductive age group. Leiomyoma, dysfunctional uterine bleeding and adenomyosis were the common clinical features and $70 \%$ of the cysts were $1-5 \mathrm{~cm}$ in size. There was no relation between morphological types of the cystic lesions and functional status. Simple serous cyst, cystic follicle, follicular cyst, cystic corpus luteum, corpus luteal cyst, theca luteal cyst, epithelial inclusion cyst and haemorrhagic cyst were found of which follicular cyst was the commonest (40\%) Multicystic non neoplastic lesions or polycystic ovaries were not found during the period of study.

Keywords: Corpus Luteal Cyst, Endometriotic Cyst, Follicular Cysts, Haemorrhagic Cyst, Polycystic Ovaries, Simple Serous Cysts, Theca Luteal Cyst.

\section{Introduction}

Neoplastic ovarian lesions have been extensively studied, but less attention is paid to non-neoplastic cystic lesions. Though follicular cysts are the most common of the non-neoplastic cysts, the \% of occurance of individual neoplastic cysts is not known. Also there is often dilemma in reporting the exact type of nonneoplastic cyst. A couple of multicystic ovaries with PCOD like morphology appeared for histopathological examination in the months prior to this study. So, this study was planned with the objectives of assessing percentage of non neoplastic cystic ovaries, determining the morphological forms and relation of the various cysts with age of patient, and to detect whether multicystic non neoplastic lesions are more frequent in present day.

\section{Materials and Methods}

A prospective hospital based cross sectional nonneoplastic ovarian cysts study was done between January to June 2019 in a tertiary hospital. All hysterectomy specimens received in the pathology department with the accompanying ovary/ovaries were included in the study. Unilateral/Bilateral oophrectomy specimens were included in this study. Autolysed samples were excluded. All specimens were photographed and gross description were recorded. Each cyst was sectioned, processed and stained with $\mathrm{H} \& \mathrm{E}$ stain using standard histological technique. Microscopic features were assessed. Data was tabulated in MS excel sheet. Percentage of occurrences of age, size, morphological type, laterality and complaints v/s type of cyst were calculated.

Criteria used for labeling various cysts were ${ }^{1,2}$.

Simple serous cyst (SSC)-Cystic space lined by single epithelial cells \& filled with fluid. Cystic follicles (CF) and follicular cyst (FC) - Inner layer of granulosa cells and outer layer of theca interna cells $(<2.5 \mathrm{~cm}$ and $>2.5 \mathrm{~cm}$ respectively). 
Cystic corpus luteum (CCL) and corpus luteal cyst (CLC)- Inner connective tissue layer, a middle layer of large luteinized granulosa cells and an outer layer of small luteinized theca interna cells $(<2.5 \mathrm{~cm}$ and $>2.5 \mathrm{~cm}$ respectively).

Theca luteal cyst (TLC)-Marked lutenization of theca interna cells, compared to granulosa cells.

Polycystic ovaries (PCO)- Multiple follicular cysts or cystic follicles with varying degrees of luteinization of the theca interna, covered by a dense fibrous capsule.

Endometriotic cyst (EC) - Cysts lined by endometrial epithelium, presence of endometrial stroma, or presence of haemosiderin laden macrophages. (Any Two out of these three criteria).

Haemorrhagic cyst (HC)- When only haemorrhage and haemosiderin laden macrophages are seen but endometrial glands \& stroma are not seen. They were further classified according to lining seen into haemorrhagic cystic corpus luteum (HCCL), haemorrhagic corpus luteal cyst (HCLC), haemorrhagic cystic follicles (HCF), haemorrhagic follicular cyst (HFC) and haemorrhagic simple serous cyst (HSSC).

Epithelial inclusion cyst (EIC)-Cyst within stroma or ovary and lined by surface epithelium.

\section{Result}

193 ovaries were received, $50 \%$ had non neoplastic cystic lesions. Non neoplastic cysts were associated with fibroid in $54 \%$, DUB in $17 \%$ and adenomyosis in $16 \%$ cases.
It can be seen from Table 1 that $\%$ of simple serous cyst and cystic follicle comprised $32 \%$ each followed by haemorrhagic cyst. Polycystic ovaries and endometriotic cyst were not seen during the study period. Hemorrhagic cysts included haemorrhagic cystic corpus luteum (7.4\%), haemorrhagic corpus luteal cyst $(1.0 \%)$, haemorrhagic cystic follicles $(4.3 \%)$, haemorrhagic follicular cyst (1.0\%) and haemorrhagic simple serous cyst (1.0\%).

Although it is not scientifically proper to split age group for ovarian cysts into groups of 20 years, it is done in this study as comparative studies have grouped them in such a manner.

It can be seen from Table 2 that No cases were seen below 20 years. $54 \%$ of non-neoplastic cystic lesions were found between 40-59 years and 45\% between 20-39 years. 1 case each of haemorrhgic cystic corpus luteum, simple serous cyst and epithelial inclusion cyst were seen in post-menopausal women. A surprising finding was cystic follicle seen in a 60 year patient.

It can be seen from Table 3 that $86 \%$ of non neoplastic cystic lesions were unilateral. Both cases of theca luteal cyst were detected, surprisingly unilateral. Also surprising were bilateral 3 cases of Simple serous cyst, 5 of cystic follicles and 2 of follicular cysts.

It can seen from Table 4 that $74 \%$ non neoplastic cystic lesions were of $1-5 \mathrm{~cm}$ in size and only $5 \%$ were larger than $5 \mathrm{~cm}$.

Table 1: Morphological types of non-neoplastic cystic lesions.

\begin{tabular}{|c|c|c|}
\hline Sr No. & Non-neoplastic cyst & Percentage \\
\hline 1. & Simple serous cyst(SSC) & $32.6 \%$ \\
\hline 2. & Cystic follicle (CF) & $32.6 \%$ \\
\hline 3. & Follicular cyst (FC) & $7.5 \%$ \\
\hline 4. & Cystic Corpus luteum (CCL) & $6.3 \%$ \\
\hline 5. & Corpus luteal cyst (CLC) & $2.1 \%$ \\
\hline 6. & Theca luteal cyst(TLC) & $-1 \%$ \\
\hline 7. & Polycystic ovary(PCO) & - \\
\hline 8. & Endometriotic cyst(EC) & $02(2.1 \%)$ \\
\hline 9. & Epithelial inclusion cyst(EIC) & $14(14.7 \%)$ \\
\hline 10. & Haemorrhagic cyst(HC) & $95(100 \%)$ \\
\hline
\end{tabular}

Table 2: Age wise distribution of Benign non-neoplastic cystic lesion (In years).

\begin{tabular}{|c|c|c|c|c|}
\hline Non-neoplastic & $\mathbf{2 0 - 3 9}$ & $\mathbf{4 0 - 5 9}$ & > $=60$ & Total \\
\hline Simple serous cyst & 10 & 21 & - & 31 \\
\hline Cystic follicle & 23 & 07 & 01 & 31 \\
\hline
\end{tabular}




\begin{tabular}{|c|c|c|c|c|}
\hline Non-neoplastic & $\mathbf{2 0 - 3 9}$ & $\mathbf{4 0 - 5 9}$ & $\mathbf{> = 6 0}$ & - \\
\hline Follicular cyst & 01 & 06 & - & 07 \\
\hline Cystic corpus luteum & 02 & 04 & - & 06 \\
\hline Corpus luteal cyst & 01 & 01 & - & 02 \\
\hline Theca luteal cyst & - & 02 & - & 02 \\
\hline Epithelial inclusion cyst & - & 02 & - & \\
\hline Haemorrhagic cyst & 01 & 06 & - & \\
(H cystic CL) & 01 & 00 & - & \\
(H CL cyst) & 02 & 02 & - & \\
(H CF) & 01 & 00 & - & $\mathbf{0 1 ( 1 . 0 \% )}$ \\
(H FC) & 01 & $\mathbf{5 1 ( 5 3 . 7 \% )}$ & \\
\hline (H SSC) & $\mathbf{4 3 ( 4 5 . 3 \% )}$ & & \\
\hline
\end{tabular}

Table 3: Unilateral\& Bilateral Benign non-neoplastic cystic lesion.

\begin{tabular}{|c|c|c|}
\hline Non-neoplastic & Unilateral & Bilateral \\
\hline Simple serous cyst & 28 & 03 \\
\hline Cystic follicle & 26 & 02 \\
\hline Follicular cyst & 05 & - \\
\hline Cystic corpus luteum & 06 & - \\
\hline Corpus luteal cyst & 02 & - \\
\hline Theca luteal cyst & 02 & - \\
\hline Epithelial inclusion cyst & 02 & 01 \\
\hline Haemorrhagic cyst & 06 & 01 \\
\hline (H cystic CL) & - & - \\
(H CL cyst) & 04 & 01 \\
(H CF) & - & - \\
\hline (H FC) & 01 & $\mathbf{1 3 ( 1 3 . 7 \% )}$ \\
\hline (H SSC) & $\mathbf{8 2 ( 8 6 . 3 \% )}$ & 01 \\
\hline
\end{tabular}

Table 4: Size of Benign non-neoplastic cystic lesions(cms).

\begin{tabular}{|c|c|c|c|}
\hline Non-neoplastic & $<1$ & $\mathbf{1 - 5}$ & $\mathbf{6 - 1 0}$ \\
\hline Simple serous cyst & 05 & 23 & 03 \\
\hline Cystic follicle & 11 & 20 & 00 \\
\hline Follicular cyst & 00 & 06 & 01 \\
\hline Cystic corpus luteum & 01 & 05 & - \\
\hline Corpus luteal cyst & 00 & 02 & - \\
\hline Theca luteal cyst & - & - & - \\
\hline Epithelial inclusion cyst & 02 & 06 & - \\
\hline Haemorrhic cyst & 01 & 01 & - \\
H cystic CL & - & 04 & - \\
H CL cyst & - & - & - \\
H CF & - & 01 & $\mathbf{0 5 ( 5 . 3 \% )}$ \\
H FC & $\mathbf{2 0 ( 2 1 . 0 \% )}$ & \\
\hline H SSC & & $\mathbf{7 0 ( 7 3 . 7 \% )}$ & - \\
\hline
\end{tabular}




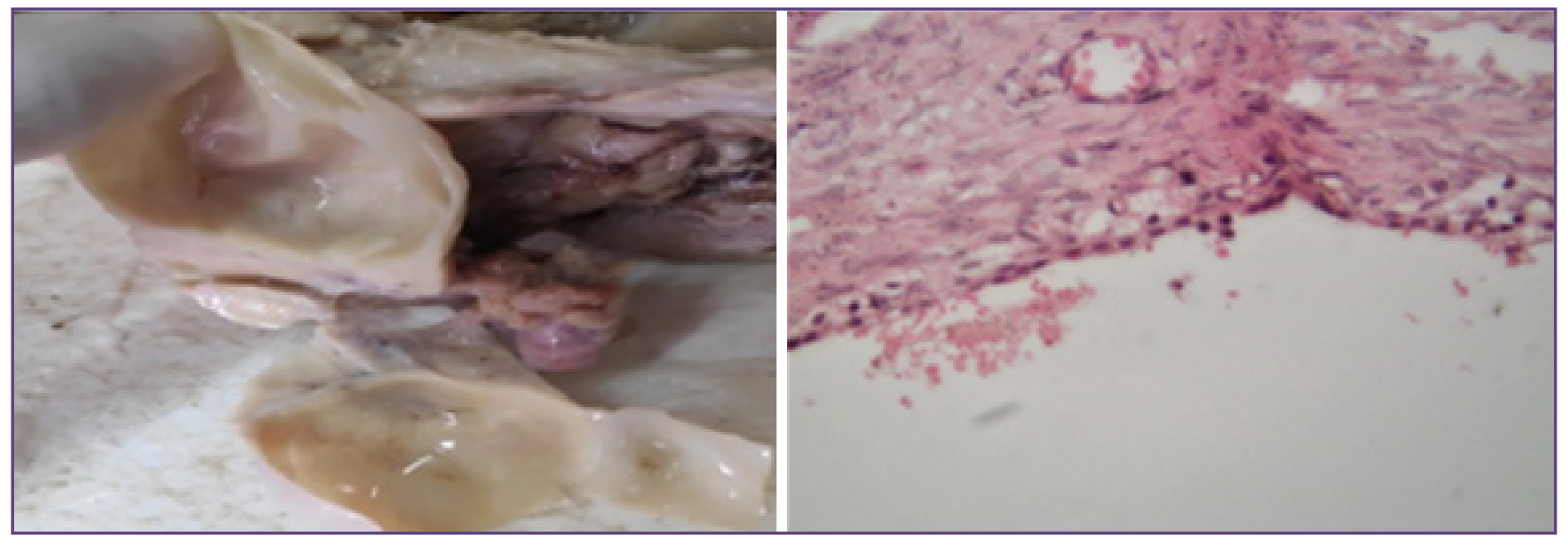

Fig. 1: a:SSC:Cut open,Smooth,Thin wall,b:SSC:Single layer epithelium(H\&E,10X) Unilocular.

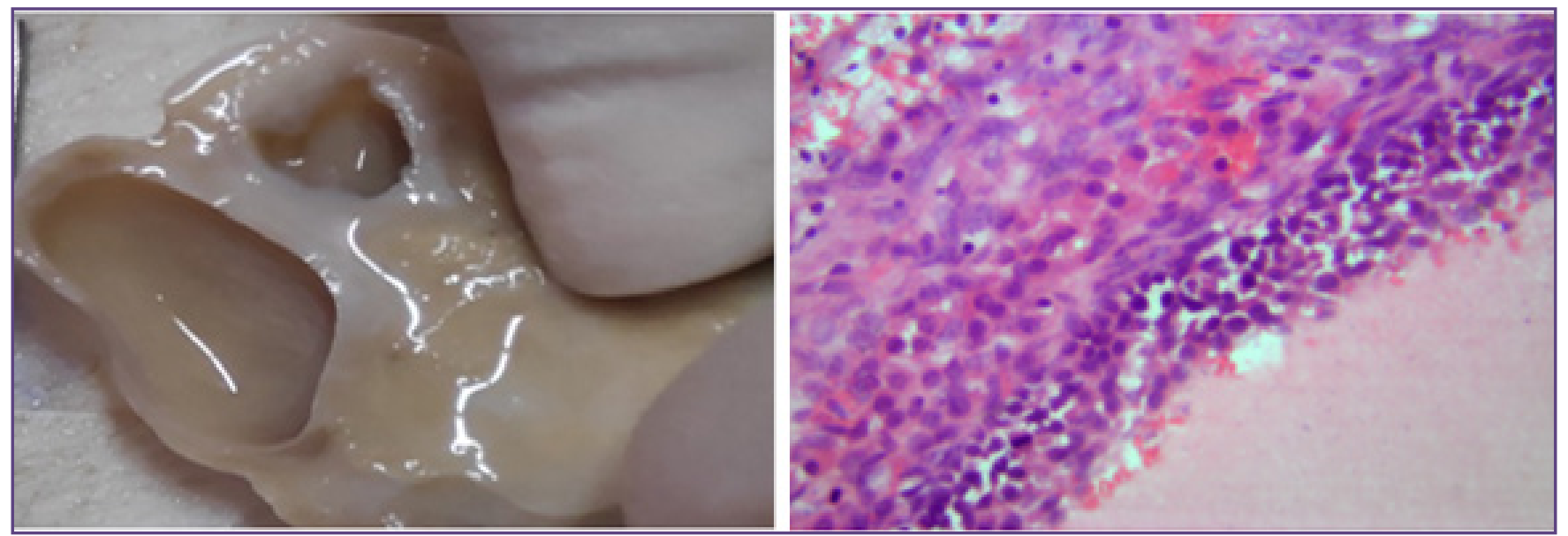

Fig. 2: a: CF:Cut open, Smooth, Thicker walledb:CF:Outer theca layer, inner granulosa Compared to SSC\&Unilocularand with fluid(H\&E,10X).

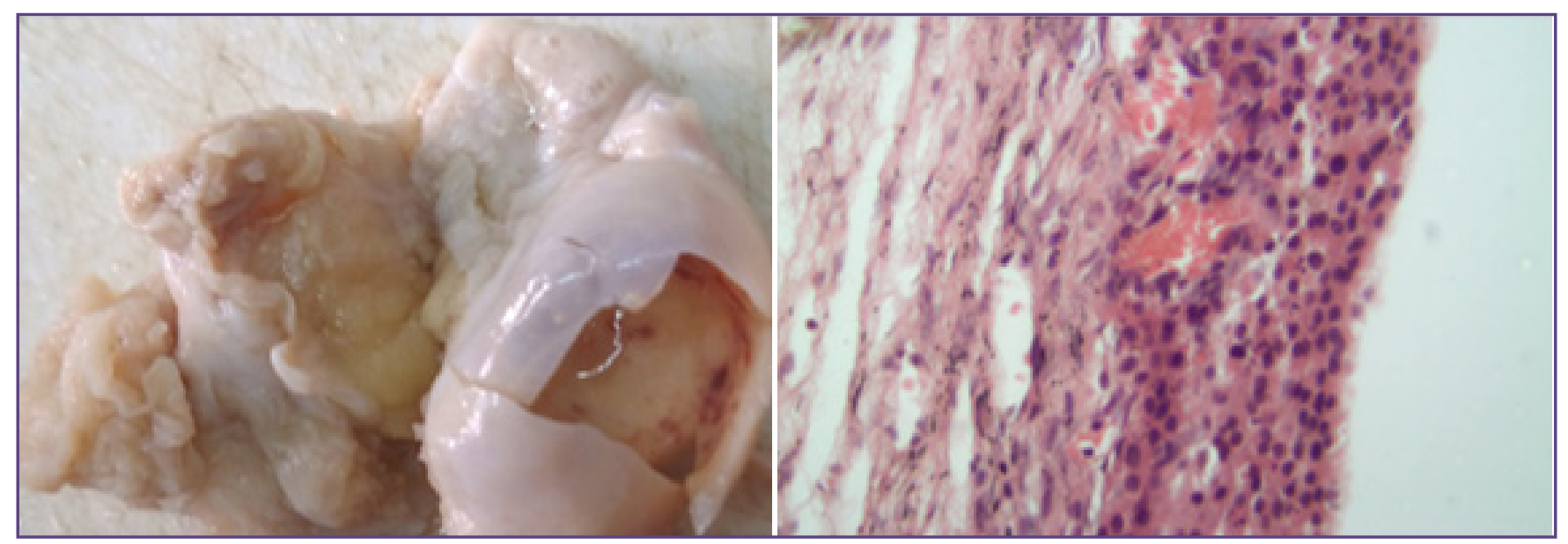

Fig 3: a:FC:Partly cut, similar to CF but>2.5cmb:FC:Outer theca\&inner granulosa layer (H\&E,10X). 


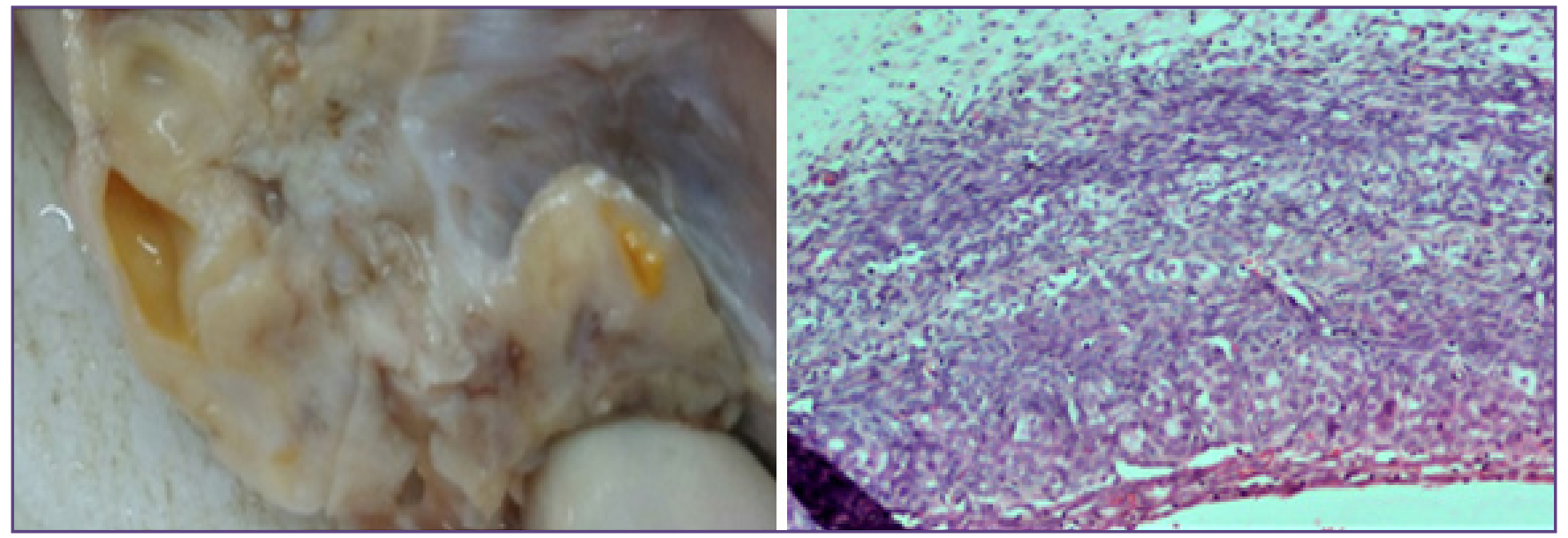

Fig. 4: a:CCL\&CLC: Cut open, Single, Unilocular, b:CCL\&CLC:Luteinized granulose layer Yellow surface\&theca layer(H\&E, 10X).

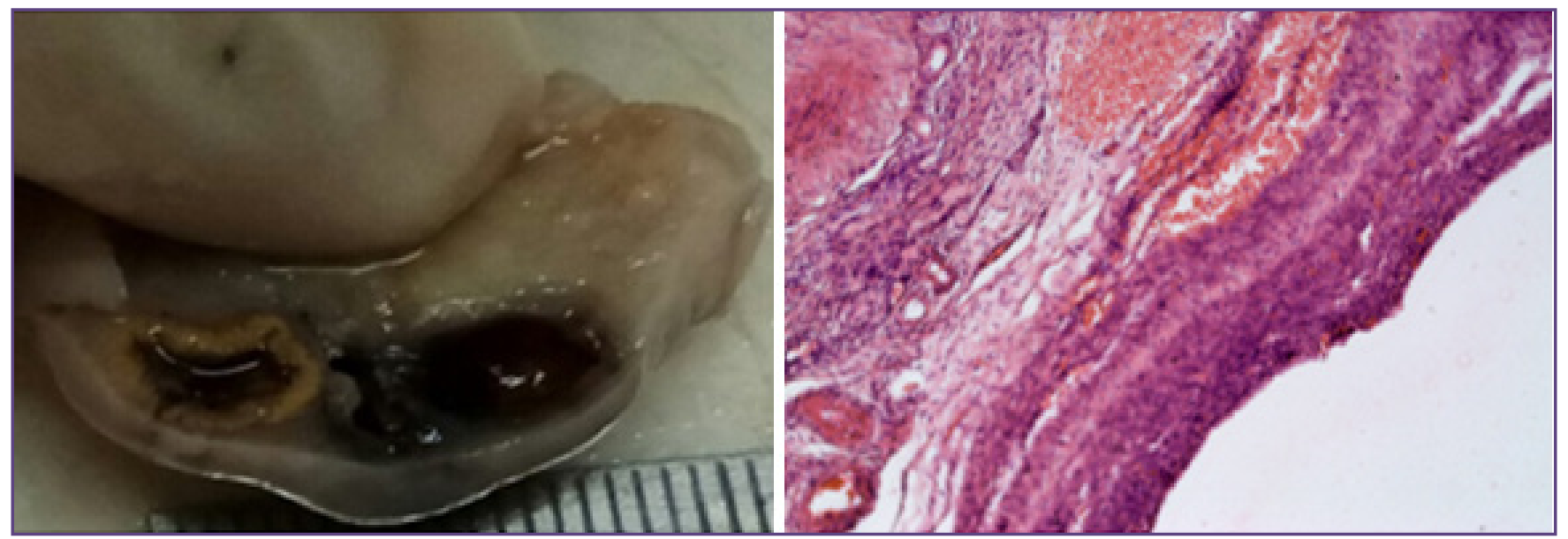

Fig. 5: a:TLC:Cut openb:TLC:Marked luteinization(H\&E,10X).
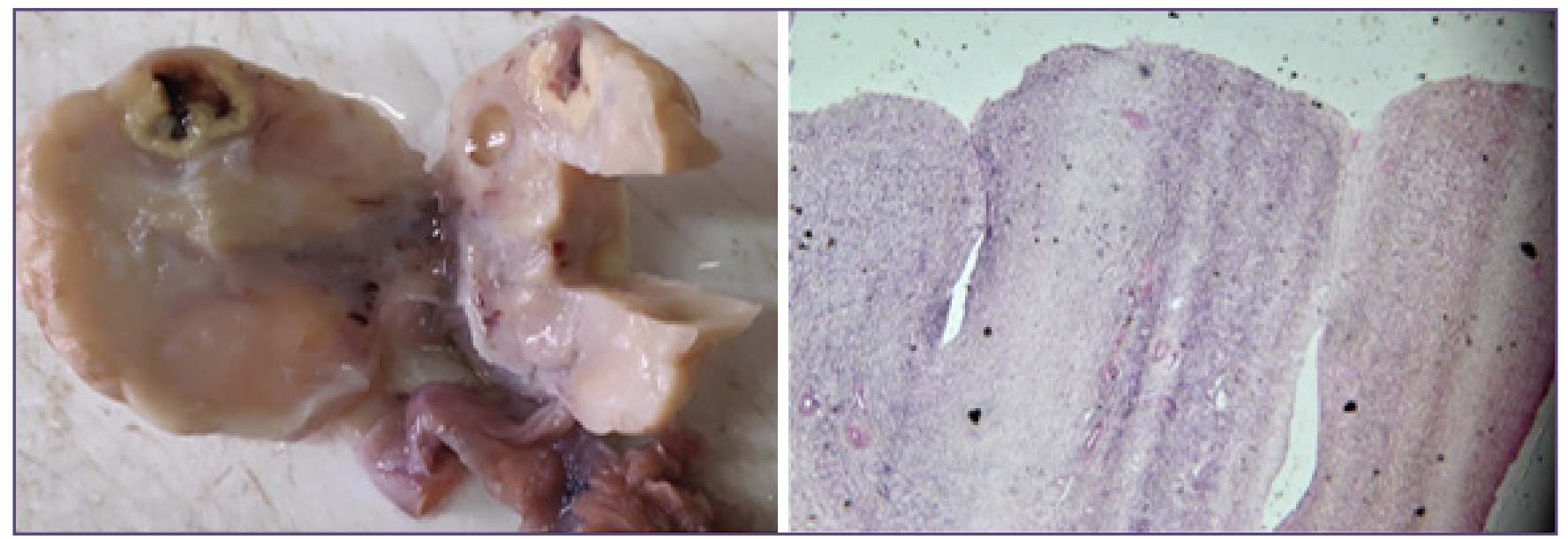

Fig. 6: a:EIC:b:EIC:Inclusion of surface epithelium(H\&E,40X). 


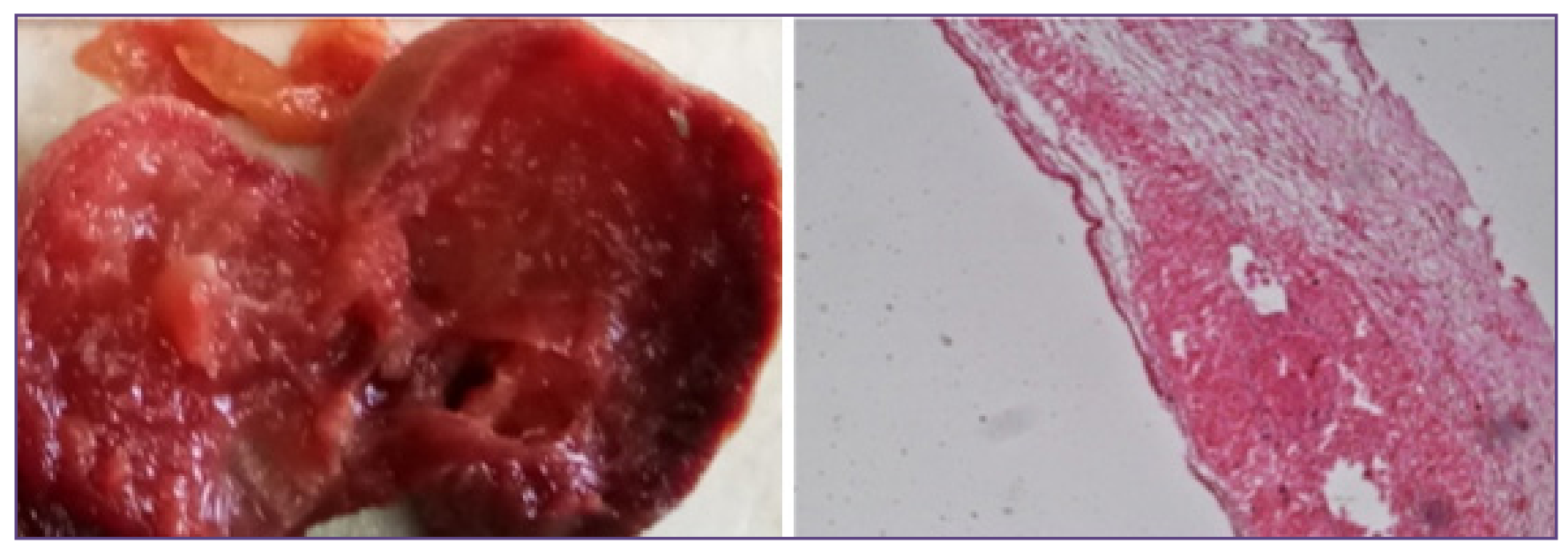

Fig. 7: a:HC:Cut openb:HC:Very thin granulosa and theca layer and marked interstitial haemorrhge(H\&E,4X).

\section{Disscussion}

Non-neoplastic cysts seen in this study were simple serous cyst, cystic follicles, follicular cysts, cystic corpus luteum, corpus luteal cyst, theca luteal cyst, epithelial inclusion cyst and haemorrhagic cyst.

It can be seen from Table5 that ratio of non-neoplastic cysts to neoplastic cysts in the studies of Haque E et al \& Sawant A et al is 3:1 or less.whereas it was 2:1 in Modi PJ et al and $1: 1$ in Dhakal $\mathrm{R}$ et al. The \% of non neoplastic cysts in Rasheed F et al is very less, as they have included only those cysts which are more than $3 \mathrm{~cm}$, hence their \% of non-neoplastic cysts may be less.

It can be seen that different types of non-neoplastic cysts are predominant in different studies. Haque et al and Rasheed et al have not included non-neoplastic conditions like theca luteal cysts and polycystic ovaries in their studies. Simple serous cyst was highest in Modi et al, follicular cyst in Savant et al and Dhakal et al, corpus luteal cyst in Rashed et al and endometriosis in Haque et al.
The present study had more number of follicular over simple serous cyst and a higher percentage of haemorrhagic cyst compare to other studies.

In all studies mentioned in Table $7,5-7 \%$ of the non neoplastic cysts were seen below 20 years. Commonest age group showing non-neoplastic cysts was 20-39years followed by $40-59$ years $((40-60 \%$ and $30-50 \%$ respectively) in different studies. In present study nonneoplastic cysts were maximally seen in $40-59$ year group. Only $1-5 \%$ cysts were seen above 60 years in different studies. In this study also $1 \%$ of the cysts were seen above 60 years. 1 case each of haemorrhgic cystic corpus luteum, simple serous cyst and epithelial inclusion cyst were seen in post-menopausal women and 1 case of cystic follicle seen in a 60 year patient. These were surprising findings for post-menopausal women. The reason for this cyst could not ascertained. However, all the cysts were $<1 \mathrm{~cm}$ in size.

Table 5: Percentage of non-neoplastic to neoplastic cysts in various studies.

\begin{tabular}{|c|c|c|}
\hline & Non-neoplastic(\%) & Neoplastic(\%) \\
\hline${\text { Haque } \mathrm{E} \mathrm{et} \mathrm{al}^{3}}$ & 71.4 & 28.6 \\
\hline Rasheed $\mathrm{F} \mathrm{et} \mathrm{al}^{4}$ & 15 & Not part of study \\
\hline Modi PJ et al $^{5}$ & 67.53 & 39.3 \\
\hline Dhakal R et al $^{6}$ & 55.9 & 23.1 \\
\hline Sawant A et al & \\
\hline Present Study & 76.9 & Not part of study \\
\hline
\end{tabular}

Table 6: Morphological types of non-neoplastic cystic lesions of ovary in different studies.

\begin{tabular}{|c|c|c|c|c|c|c|c|c|}
\hline Types & SSC & FC & CLC & TLC & PCO & EC & EIC & HC \\
\hline Haque E et al $^{3}$ & 11.5 & 35.2 & 27.2 & - & - & 24.3 & - & - \\
\hline Rasheed F et al $^{4}$ & - & 33.3 & 53.3 & - & - & 13.3 & - & - \\
\hline Modi PJ et al $^{5}$ & 49 & 12.5 & 16.8 & - & - & 9.1 & 2.4 & 2.9 \\
\hline
\end{tabular}




\begin{tabular}{|c|c|c|c|c|c|c|c|c|}
\hline Types & SSC & FC & CLC & TLC & PCO & EC & EIC & HC \\
\hline Dhakal $\mathrm{R} \mathrm{et} \mathrm{al}^{6}$ & 29.8 & 55.3 & 4.3 & - & - & - & - & 10.6 \\
\hline Sawant A et al & & 10 & 70 & 12.7 & - & - & 1.8 & - \\
\hline Present Study & 32.6 & 40.1 & 8.4 & 2.1 & - & - & 2.1 & 14.7 \\
\hline
\end{tabular}

Table 7: Age distribution in percentage in different studies.

\begin{tabular}{|c|c|c|c|c|}
\hline Age $(\mathrm{yrs})$ & $\mathbf{0 - 1 9}$ & $\mathbf{2 0 - 3 9}$ & $\mathbf{4 0 - 5 9}$ & $\mathbf{3 0}$ \\
\hline Haque E et al $^{3}$ & 7.4 & 58.4 & 32.9 & 1.3 \\
\hline Rasheed $\mathrm{F} \mathrm{et} \mathrm{al}^{4}$ & 6.7 & 60 & 33.3 & 0 \\
\hline Modi PJ et al $^{5}$ & 2.88 & 53.4 & 38.5 & 5.3 \\
\hline Dhakal R et al $^{6}$ & 6.38 & 44.68 & 48.93 & 0 \\
\hline Prakash Study et al $^{8}$ & 5.7 & 53.4 & 36.6 & 4.3 \\
\hline Kar Studyet al & & 41.7 & 46.2 & 4.4 \\
\hline Present Study & - & 45.3 & 53.7 & 1.0 \\
\hline
\end{tabular}

\section{Conclusion}

Non neoplastic cystic ovaries comprised $50 \%$ of all ovarian lesions in oophrectomy specimens received. $83 \%$ were seen during reproductive age. The commonly associated clinical features were leiomyoma, dysfunctional uterine bleeding and adenomyosis. $70 \%$ of the cysts were $1-5 \mathrm{~cm}$ in size. There was no relation between morphological types of the cystic lesions and functional status. Simple serous cyst, cystic follicle, follicular cyst, cystic corpus luteum, corpus luteal cyst, theca luteal cyst, epithelial inclusion cyst and haemorrhagic cyst were found of which follicular cyst was the commonest morphological type $(40 \%)$ Multicystic non neoplastic lesions or polycystic ovaries were not found during the period of study.

\section{Bibliography}

1. Rosai J, Ackerman LV. Rosai and Ackerman's surgical pathology. 1. Mosby; 2004.

2. SJ R. Robboy's pathology of the female reproductive tract. Edinburgh: Churchill Livingstone Elsevier. 2009:611.

3. Haque E, Huq N, Yusuf A. Non-neoplastic Cystic Lesions of Ovary. histopathology.;1:2.
4. Fatima R, Sandhya M, Sowmya TS. Study of histomorphological pattern of ovarian neoplastic and nonneoplastic lesions. International Journal of Research in Medical Sciences. 2017 May;5(5):2095-8.

5. Modi PJ, Bhalodia JN, Shah NM. Histopathological analysis of non-neoplastic lesions of ovary: A study at tertiary care hospital in western region of India. International Journal of Medical Science and Public Health. 2018 Oct 1;7(10):843-8.

6. Dhakal R, Makaju R, Bastakoti R. Clinico-morphological Spectrum of Ovarian Cystic Lesions. Kathmandu Univ Med J. 2016;53(1):13-6.

7. Sawant A, Mahajan S. Histopathological study of ovarian lesions at a tertiary health care institute. MVP Journal of Medical Science. 2017 May 22;4(1):26-9.

8. Prakash A, Chinthakindi S, Duraiswami R, Indira V. Histopathological study of ovarian lesions in a tertiary care center in Hyderabad, India: a retrospective five-year study. Int J Adv Med. 2017 May;4(3):745.

9. Kar T, Kar A, Mohapatra PC. Intra-operative cytology of ovarian tumors. J Obstet Gynecol India. 2005;55(4):345-9.

*Corresponding author:

Dr. Seema N. Baxi, Postal Address: 2201 A-1/2, FulwadiChowk, Hill Drive, Bhavnagar- 364002, Gujarat, India

Phone: +91 9327539054

Email: seemabaxi@yahoo.com

Date of Submission : 11/12/2019

Financial or other Competing Interests: None. 